\title{
Cavernous Hemangioma of the Conjunctiva
}

\author{
Noopur Deokinandan Nayak Shinkre, MD; Ugam P.S. Usgaonkar, MD \\ Department of Ophthalmology, Goa Medical College, Goa, India \\ ORCID: \\ Noopur Deokinandan Nayak Shinkre: http://orcid.org/0000-0001-5503-2710
}

J Ophthalmic Vis Res 2021; 16 (2): 303-305

\section{PRESENTATION}

A 23-year-old healthy male presented to our outpatient department with complaint of foreign body sensation and a painless, red mass on the nasal side of his right eye, which he had noticed approximately six months before. It had gradually increased to attain its present size.

On examination, his visual acuity on Snellen's chart was 20/20 in both eyes. Examination of his right eye revealed a bright red, vascular, smooth, lobulated mass on the nasal side of the bulbar conjunctiva, measuring approximately $5 \times 5 \times 4 \mathrm{~mm}$, with tortuous and engorged conjunctival vessels at the base of the lesion [Figure 1a]. The lesion was mobile and did not exhibit pulsations. Other findings of his ocular examination were unremarkable. No similar lesions were detected elsewhere on his body.

A clinical diagnosis of conjunctival hemangioma was made. The lesion was surgically excised under topical anesthesia. No extension was noted beyond the tenon's capsule. Histopathological examination of the lesion revealed a cavernous hemangioma of the bulbar conjunctiva [Figure 1b]. Postoperatively, the patient was treated with topical antibiotics and steroid eye drops [Figure 2].

\section{Correspondence to:}

Noopur Deokinandan Nayak Shinkre, MD. Department of Ophthalmology, Goa Medical College, Goa, India.

E-mail: noopur.shinkre@gmail.com

Received: 14-08-2019 Accepted: 25-03-2020

\section{Access this article online}

Website: https://knepublishing.com/index.php/JOVR

DOI: 10.18502/jovr.v16i2.9097

\section{DISCUSSION}

Cavernous hemangiomas are vascular malformations characterized pathologically by large, thin-walled, and cystically dilated blood vessels. They are rare vascular tumors of the ocular surface; unlike capillary hemangioma, lymphangioma, and pyogenic granuloma which are more common. ${ }^{[1,2]}$

Occurrence of an isolated cavernous hemangioma of the conjunctiva has rarely been reported to date. In addition to the results of the surveys conducted by Elsas et $\mathrm{al}^{[3]}$ and Shields et $a{ }^{[2,4]}$ to the best of our knowledge, only nine cases have been reported in the English literature, and notably, most of them have occurred in young males. The reported lesions arose from either the caruncle or the temporal side of the bulbar conjunctiva. However, in our case, unlike the previously reported cases, the tumor was located on the nasal side of the bulbar conjunctiva, neither overlying nor involving the caruncle, thus making it, to the best of our knowledge, the first such case to be reported.

In these cases, the primary concern is purely cosmesis. However, some cases may be associated with recurrent subconjunctival hemorrhage. Excisional biopsy of the tumor is considered to be the treatment of choice. ${ }^{[5]}$

This is an open access journal, and articles are distributed under the terms of the Creative Commons Attribution-NonCommercial-ShareAlike 4.0 License, which allows others to remix, tweak, and build upon the work non-commercially, as long as appropriate credit is given and the new creations are licensed under the identical terms.

How to cite this article: Noopur Deokinandan Nayak Shinkre, Ugam P.S. Usgaonkar. Cavernous Hemangioma of the Conjunctiva. J Ophthalmic Vis Res 2021;16:303-305. 


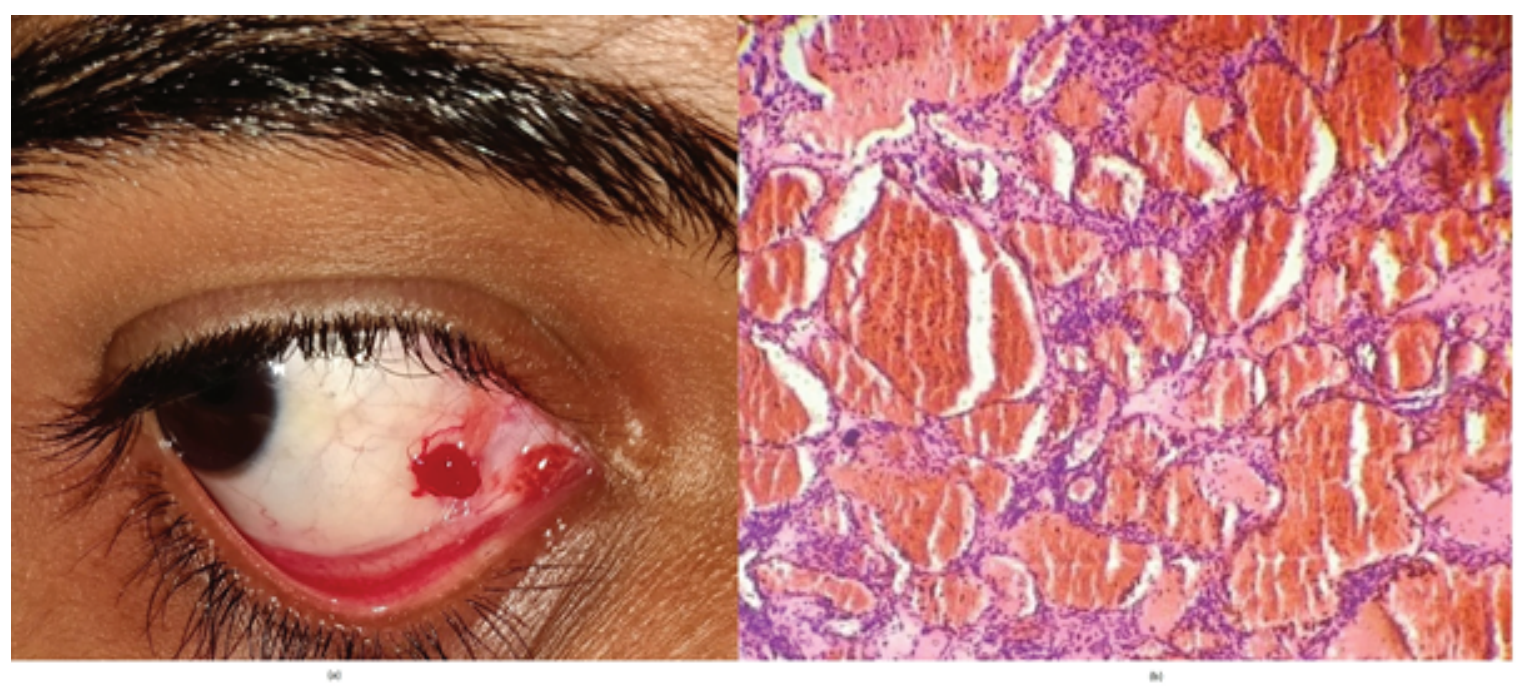

Figure 1. (a) Image showing a bright red, smooth, lobulated mass on the nasal side of the bulbar conjunctiva with tortuous conjunctival vessels at its base. (b) Histopathological evaluation of the lesion showing multiple, blood-filled cavernous spaces surrounded by a fibromyxoid stroma (hematoxylin and eosin, 10x magnification).

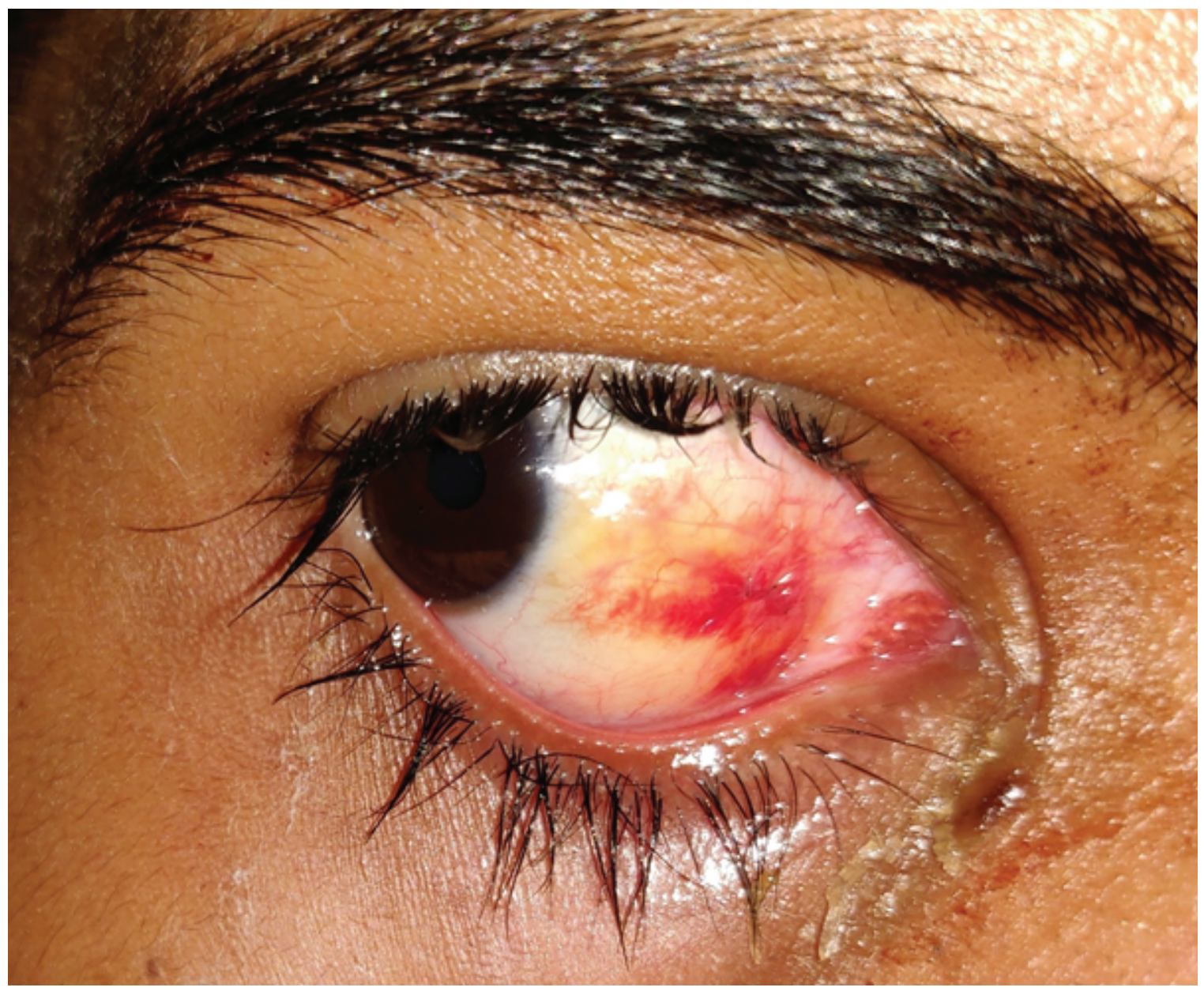

Figure 2. Image acquired one day after excision of the lesion. The conjunctival defect is apposed with 10-0 nylon sutures. 


\section{Declaration of Patient Consent}

The authors certify that they have obtained all appropriate patient consent forms. In the form the patient has given his consent for his images and other clinical information to be reported in the journal. The patient understand that his name and initial will not be published and due efforts will be made to conceal his identity, but anonymity cannot be guaranteed.

\section{Financial support and sponsorship}

Nil.

\section{Conflicts of interest}

There are no conflicts of interest.

\section{REFERENCES}

1. Shields CL, Shields JA. Tumors of the conjunctiva and cornea. Surv Ophthalmol 2004;49:3-24.

2. Shields JA, Mashayekhi A, Kligman BE, Kunz WB, Criss J, Eagle Jr RC, et al. Vascular tumors of the conjunctiva in 140 cases. Ophthalmology 2011;118:1747-1753.

3. Elsas FJ, Green WR. Epibulbartumors in childhood. Am J Ophthalmol 1975;79:1001-1007.

4. Shields CL, Demirci H, Karatza E, Shields JA. Clinical survey of 1643 melanocytic and nonmelanocytic conjunctival tumors. Ophthalmology 2004;111:1747-1754.

5. Honavar SG, Manjandavida FP. Tumors of the ocular surface: a review. Indian J Ophthalmol 2015;63:187-203. 